\title{
INFLUÊNCIA DAS ÉPOCAS DE CULTIVO E DO ESTABELECIMENTO DO CONSÓRCIO NA PRODUÇÃO DE TOMATE E ALFACE CONSORCIADOS
}

\author{
Influence of planting and intercropping establishment time on production \\ of the cultures intercropping of tomato and lettuce
}

\begin{abstract}
Bráulio Luciano Alves Rezende ${ }^{1}$, Gustavo Henrique Domingues Canato ${ }^{2}$, Arthur Bernardes Cecílio Filho ${ }^{3}$ RESUMO

Conduziu-se este trabalho na UNESP, Jaboticabal-SP, em duas épocas de cultivo, julho a novembro de 2001 e fevereiro a agosto de 2002, com o objetivo de avaliar a produtividade das culturas de tomate e de alface em cultivo consorciado, em função da época de estabelecimento do consórcio. Em cada época, foram avaliados nove tratamentos, sendo os consórcios e os monocultivos de alface estabelecidos aos zero, 14, 28 e 42 dias após o transplantio do tomateiro. As cultivares de tomate e alface foram, respectivamente, Débora Max e Vera. A produtividade comercial do tomateiro, bem como a classificação de frutos de tomate não foram influenciadas pela presença da alface. Entretanto, a produtividade da alface foi menor no cultivo consorciado do que em monocultivo e quanto mais tardio o transplantio da alface em relação ao tomateiro, maior foi a redução no acúmulo de massa seca de plantas de alface. Os consórcios estabelecidos com o transplantio da alface até 14 dias após o transplantio do tomateiro obtiveram os melhores resultados segundo o índice de Uso Eficiente da Terra.
\end{abstract}

Termos para indexação: Lycopersicon esculentum, Lactuca sativa, sistema de cultivo, cultivo consorciado.

\section{ABSTRACT}

This work was carried out at UNESP, Jaboticabal-SP, in two times of cultivation, July to November of 2001 and February to August of 2002, with objective to evaluate the productivity of tomato and lettuce crops in intercropping, in function of the time of establishment of intercropping (time of lettuce's transplanting). Nine treatments were evaluated, with the intercropping and monoculture of lettuce at zero, 14, 28 and 42 days after the transplant of tomato. The cultivars of tomato and lettuce were, respectively, Debora Max and Vera. The commercial productivity of tomato, as well as the classification of tomato fruits were influenced by the presence of the lettuce. However, the productivity of the lettuce was smaller in the intercropping cultivation and so much than later was the transplant of the lettucein relation to tomato crop. The intercropping established with the transplant of the lettuce over to 14 days affter transplant of tomato showed the best results according to index of Efficient Use of the Land.

Index terms: Lycopersicon esculentum, Lactuca sativa, cultivation system, intercropping cultivation.

(Recebido para publicação em 14 de Janeiro de 2004 e aprovado em 2 de fevereiro de 2005)

\section{INTRODUÇÃO}

A eficiência e as vantagens de um sistema consorciado fundamentam-se, principalmente, na complementaridade entre as culturas envolvidas, sendo que serão tanto maiores quanto menores forem o(s) efeito(s) negativo(s) estabelecido(s) de uma cultura sobre a outra (CERETTA, 1986). Por isso, torna-se muito importante avaliar o manejo das espécies em cultivo consorciado, a fim de se ter menor competição pelos recursos a serem utilizados pelas mesmas. Vários autores (FERREIRA e CECÍLIO FILHO, 2001; CECÍLIO FILHO e MAY, 2002; NARDIN et al., 2002; REZENDE et al., 2002a,b; REZENDE et al., 2003) verificaram que as produtividades das culturas consorciadas foram significativamente influenciadas pela época de estabelecimento do consórcio.
Além da maior densidade de plantas por unidade de área que o sistema de cultivo consorciado proporciona em relação ao monocultivo, tem-se melhor cobertura do solo, o que reduz a incidência de plantas daninhas e melhora a proteção do solo contra a erosão (BEETS, 1975; ZAFFORONI, 1987). O consórcio proporciona também um aumento na renda líquida dos cultivos (PAL e SING, 1991; GODE e BOBDE, 1993; DUBEY e KULVI, 1995; CATELAN et al., 2002).

Outras vantagens atribuídas aos cultivos consorciados são: maior eficiência na utilização da terra, diminuição dos riscos de perdas totais, melhor uso dos recursos ambientais, diminuição do uso de insumos não renováveis, tais como fertilizantes e agrotóxicos, ou pelo menos uso mais racional dos mesmos (HORWITH, 1985).

\footnotetext{
1. Aluno de Mestrado, FCAV/UNESP - Departamento de Produção Vegetal - Prof. Paulo D. Castellane, s/n - 14.884-900 - Jaboticabal, SP - blrezende@ig.com.br

2. Engenheiro Agrônomo.

3. Professor Dr., UNESP/FCAV - rutra@fcav.unesp.br
} 
Os sistemas de cultivos consorciados, no entanto, seja entre espécies de hortaliças ou delas com outras culturas, ainda são pouco estudados. Na olericultura, o consórcio tem elevado potencial de utilização por parte de pequenos produtores, os quais dispõem de mão-deobra familiar e pequeno capital de investimento. A escolha criteriosa das culturas a serem consorciadas e da época das suas respectivas instalações é, de fundamental importância, para que se possa otimizar as vantagens deste sistema (TRENBATH, 1975).

Rezende et al. (2003) constataram maior produtividade da cultura do rabanete quando em cultivo consorciado com a alface, sendo os melhores resultados obtidos com a semeadura do rabanete até sete dias após a semeadura da alface. A produtividade da alface, por outro lado, não diferiu significativamente da obtida em monocultivo. Cecílio Filho e May (2002), também observaram que a produtividade do rabanete foi maior em consorciação com alface do que em monocultivo. O consórcio estabelecido com a semeadura do rabanete no mesmo dia do transplantio da alface, proporcionou receita de $\mathrm{R} \$ 26.660,55 \mathrm{ha}^{-1}$, enquanto que, o monocultivo da alface cerca de $\mathrm{R} \$ 18.036,29 \mathrm{ha}^{-1}$.

Caetano et al. (1996) verificaram que no consórcio entre cenoura e cinco cultivares de alface, as produtividades das culturas e a qualidade dos produtos não foram prejudicadas em relação ao monocultivo.

Nardin et al. (2002) e Cecílio Filho et al. (2003) observaram que a produtividade da beterraba em monocultivo não diferiu significativamente da obtida em cultivo consorciado e que a produtividade da rúcula em monocultivo foi superior à obtida em consórcio. Entretanto, reduções na produtividade da rúcula foi siginificativamente reduzida à medida em que sua semeadura foi realizada mais tardiamente em relação ao transplantio da beterraba.

O presente trabalho teve por objetivo avaliar a produtividade das culturas de tomate e da alface em consorciação, em função das épocas de cultivo e do estabelecimento do consórcio.

\section{MATERIAL E MÉTODOS}

Os experimentos foram conduzidos em casa-devegetação, em duas épocas de cultivo, julho a novembro de 2001 e fevereiro a agosto de 2002, na UNESP, campus Jaboticabal - SP. Avaliaram-se nove tratamentos, os quais resultaram de combinações dos fatores: sistemas de cultivo (consórcio e monocultivo) e épocas de transplantio da alface $(0,14,28$ e 42 dias após o transplantio - DAT - do tomate) (Tabela 1). O experimento foi conduzido em blocos casualizados, com doze repetições.

Para o tomate foi utilizada a cultivar Débora Max e para alface a cultivar Vera. O tomateiro foi transplantado em espaçamento de $1,20 \times 0,50 \times 0,50 \mathrm{~m}$ e a alface em $0,30 \times 0,30 \mathrm{~m}$. A unidade experimental foi constituída por 8 plantas de tomate e 28 plantas de alface, perfazendo uma área total de $2,4 \mathrm{~m}^{2}$ $(1,2 \times 2,0 \mathrm{~m})$.

TABELA 1 - Caracterização dos tratamentos avaliados na etapa do experimento. UNESP, Jaboticabal (SP), 2001.

\begin{tabular}{lcc}
\hline \multicolumn{1}{c}{ Tratamentos } & Tomate & Alface (DAT*) \\
\hline $1-$ Consórcio & Presente & 0 \\
$2-$ Consórcio & Presente & 14 \\
3- Consórcio & Presente & 28 \\
$4-$ Consórcio & Presente & 42 \\
$5-$ Monocultivo tomate & Presente & Ausente \\
$6-$ Monocultivo Alface & Ausente & 0 \\
$7-$ Monocultivo Alface & Ausente & 14 \\
$8-$ Monocultivo Alface & Ausente & 28 \\
$9-$ Monocultivo Alface & Ausente & 42 \\
\hline
\end{tabular}

*dias após o transplantio do tomateiro.

Ciênc. agrotec., Lavras, v. 29, n. 1, p. 77-83, jan./fev. 2005 
As análises de solo da primeira e segunda época de cultivo mostraram, respectivamente, $\mathrm{pH}(\mathrm{CaCl} 2)$ de 6,1 e 5,7; 22 e 20 g dm-3 de matéria orgânica, 178 e $134 \mathrm{mg} \mathrm{dm}-3$ de $\mathrm{P}$ (resina). Em mmolc dm-3, as análises apresentaram 2,6 e 3,8 de K, 65 e 37 de Ca, 20 e 19 de $\mathrm{Mg}$ e saturação por bases do solo (V\%) de 83 e $73 \%$.

Foi realizada adubação foliar na alface aos 10 DAT, com $3 \mathrm{~g} \mathrm{~L}^{-1}$ de sulfato de zinco, $2 \mathrm{~g} \mathrm{~L}^{-1}$ de ácido bórico e $1,5 \mathrm{~g} \mathrm{~L}^{-1}$ cloreto de potássio. Para a cultura do tomateiro, a adubação foliar, além da realizada na mesma época da alface, também ocorreu aos 30 e 50 dias após o seu transplantio com os mesmos fertilizantes e concentrações citadas anteriormente.

A adubação de cobertura para a cultura da alface foi a mesma para ambas épocas de cultivo, sendo realizada aos 10 , 20 e 30 DAT, com 10 g planta $^{-1}$ de nitrato de amônio. Para a cultura do tomateiro, na primeira época de cultivo, foram aplicados nitrato de amônio e cloreto de potássio, respectivamente, 8 e 2 g planta $^{-1}$ aos 15 DAT, 10 e 2 g planta $^{-1}$ aos 30 DAT, 10 e $4 \mathrm{~g}$ planta $^{-1}$ aos 50 DAT, 9 e 4 g planta $^{-1}$ aos 70 DAT e 6 e 4 g planta $^{-1}$ aos 90 e 110 DAT. No segundo cultivo, foi realizada mais uma adubação de cobertura com 6 e 4 g planta $^{-1}$ de nitrato de amônio e cloreto de potássio, respectivamente, aos 125 dias após o transplantio, uma vez que o período de colheita foi maior.

$\mathrm{Na}$ primeira época de cultivo, o tomateiro foi conduzido com duas hastes, sendo podado após a quarta inflorescência de cada haste, devido a alta incidência de traça. Na segunda época de cultivo, o tomateiro também foi conduzido com duas hastes, mas foi podado após a quinta inflorescência de cada haste.

A colheita da alface foi realizada aos 42 DAT. Para melhor avaliar o efeito da consorciação sobre o acúmulo de massa seca da parte aérea (MSPA) e fresca da parte aérea (MFPA), essas características foram avaliadas separadamente para alfaces situadas nas laterais do canteiro (MFPAEx e MSPAEx) das situadas nas duas linhas internas do canteiro (MFPAIn e MSPAIn). Para a cultura do tomateiro foram realizadas colheitas, semanalmente, totalizando um ciclo de 168 dias na primeira época e 179 dias na segunda época de cultivo.

A produção comercial de tomate foi obtida pelo percentual da produção total que segundo o diâmetro dos frutos, classificou-se nas classes 4 ( 40 a 50 $\mathrm{mm}), 5(50$ a $60 \mathrm{~mm}), 6(60$ a $70 \mathrm{~mm})$ e $7(70$ a 80 $\mathrm{mm}$ ), estabelecidos pelo Programa de Adesão Voluntária, elaborada pelo Ministério da Agricultura e Abas- tecimento, Secretaria de Agricultura de São Paulo e CEAGESP.

Procedeu-se a análise conjunta das duas épocas de cultivo para as características produção comercial de tomate, distribuição percentual da produção comercial de tomate nas classes 5 e classe 6+7, MSPAEx, MSPAIn, MFPAEx, MFPAIn, diâmetro de parte aérea de plantas de alface internas (DIn) e externas (Dex).

\section{RESULTADOS E DISCUSSÃO}

Para as características do tomateiro, a análise conjunta dos cultivos mostrou que não houve interação significativa entre época de cultivo (Experimentos) e tratamentos (correspondentes às combinações entre os dois sistemas de cultivo e as quatro épocas de transplantio da alface em relação ao tomateiro). Somente houve efeito significativo do fator época de cultivo sobre a produção comercial do tomateiro nas classes 5 e $6+7$. O efeito época de cultivo retrata o melhor desempenho da cultura do tomateiro no segundo cultivo (25/02 a 24/08/2002).

A produtividade obtida na segunda época $(8,46$ $\mathrm{kg}$ planta $^{-1}$ ) foi o dobro da verificada na primeira época de cultivo, alcançando $199.078 \mathrm{~kg} \mathrm{ha}^{-1}$ de frutos comerciais, dentro da expectativa de produtividade para o híbrido, desempenho este que pode ser atribuído ao melhor desenvolvimento das plantas do tomateiro resultante, principalmente, da baixa incidência da traça, bem como de outras pragas e doenças ocorridas neste período, maior período de colheita e maior número de frutos e de melhor classificação. A produção de frutos comerciais classificada nas classes $6+7$ foi de $70,4 \%$ da produção comercial obtida na segunda época de cultivo e somente de $41,6 \%$ na primeira época.

Por outro lado, independente da época de cultivo e produtividade comercial obtida na cultura do tomateiro, não se observou efeito significativo dos tratamentos sobre a produção comercial e classificação desta nas classes 5 e $6+7$. Estes resultados demonstram que não houve influência significativa da alface sobre o tomateiro, independente da época em que foi transplantada, ou seja, da época em que foi estabelecida a consorciação das culturas.

A ausência de influência da alface sobre o tomateiro, provavelmente se deveu à grande divergência entre as espécies quanto a arquitetura, porte, velocidade de crescimento e ocupação do terreno. O desenvolvimento lento da alface nos primeiros $30 \mathrm{DAT}$, permitiu ao tomateiro atingir altura suficiente para não sofrer com a presença da alface. No entanto, o tomateiro pelo seu maior desenvolvimento na vertical promoveu sombreamento sobre a alface. 
Na primeira época de cultivo, houve efeito significativo da interação sistema de cultivo e época de transplantio da alface para todas as características da alface avaliadas. Em cultivo consorciado, maior massa seca de parte aérea de plantas de alface localizadas nas laterais do canteiro (MSPAEx), foi obtida quando a alface foi transplantada até 14 DAT do tomateiro. À medida que o transplantio da alface foi mais tardio, menor foi a MSPAEx (Tabela 2), sendo que a alface transplantada aos 28 DAT apresentou redução no acúmulo de MSPAEx de $55 \%$. O consórcio estabelecido posteriormente (42 DAT) não permitiu que as plantas de alface se desenvolvessem, decorrente do forte sombreamento proporcionado pelo tomateiro. Neste caso, as alfaces caracterizaram-se por caules muito compridos, e com baixíssimo número de folhas, as quais eram alongadas e com limbo muito estreito. As plantas de alface colhidas sob estas condições encontravam-se completamente desfiguradas, sem caracterização e, conseqüentemente, sem valor comercial, não permitindo, se quer, formar maços de alface com a junção de várias plantas.

Assim como observado para MSPAEx, a massa seca de plantas internas (MSPAIn) também reduziu acentuadamente com o aumento no número de dias para o estabelecimento do consórcio (Tabela 2). Esta redução no acúmulo de massa seca da parte aérea foi maior para as plantas internas do que constatado para plantas das laterais do canteiro. No cultivo da alface aos 14 DAT do tomateiro, houve uma queda de aproximadamente $40 \%$ no acúmulo de MSPAIn, enquanto que, para as plantas externas, na mesma época, constatou-se cerca de $13 \%$ de redução da MSPAEx. Tal fato deve ser atribuído ao maior sombreamento proporcionado pelo tomateiro às plantas de alface localizadas nas linhas internas do canteiro. Aos 28 DAT do tomateiro, obteve-se apenas $20 \%$ da MSPAIn de alface transplantada na mesma data que o tomateiro.

Massa fresca da parte aérea de plantas de alface situadas lateralmente (MFPAEx) e internamente (MFPAIn) ao canteiro, tiveram comportamento semelhante à massa seca das plantas. Em ambos os casos, a alface apresentou maior peso médio de plantas em monocultivo e, em consórcio, as reduções nas MFPAEx e MFPAIn ocorreram progressivamente à medida que o período transcorrido entre o transplantio da alface e do tomateiro foi maior (Tabela 3) .

TABELA 2 - Massa seca da parte aérea de plantas de alface situadas nas laterais do canteiro (MSPAEx) e internamente (MSPAIn) em função do sistema de cultivo e época de transplantio de alface, na $1^{\mathrm{a}}$ época e $2^{\mathrm{a}}$ de cultivo. UNESP, Jaboticabal (SP), 2002.

\begin{tabular}{|c|c|c|c|c|}
\hline \multirow{3}{*}{ Sistema de cultivo } & \multicolumn{4}{|c|}{ 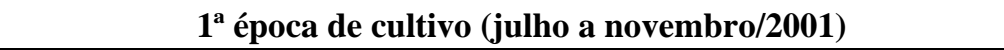 } \\
\hline & \multicolumn{4}{|c|}{ MSPAEx $\left(\right.$ gplanta $\left.^{-1}\right)$} \\
\hline & O DAT ${ }^{1}$ & 14 DAT & 28 DAT & 42 DAT \\
\hline Consórcio & $6,12 \mathrm{Ba}^{2}$ & $5,34 \mathrm{Ba}$ & $2,81 \mathrm{Bb}$ & $0,78 \mathrm{Bc}$ \\
\hline \multirow[t]{2}{*}{ Monocultivo } & 8,27Aab & 6,94Ac & 7,33Abc & 9,50Aa \\
\hline & \multicolumn{4}{|c|}{ MSPAIn (gplanta ${ }^{-1}$ ) } \\
\hline Consórcio & $6,01 \mathrm{Ba}^{2}$ & $3,52 \mathrm{Bb}$ & $1,17 \mathrm{Bc}$ & $0,57 \mathrm{Bc}$ \\
\hline \multirow[t]{3}{*}{ Monocultivo } & $9,43 \mathrm{Ab}$ & 7,11Ac & $8,50 \mathrm{Abc}$ & $11,20 \mathrm{Aa}$ \\
\hline & \multicolumn{4}{|c|}{$2^{2 \mathrm{a}}$ época de cultivo (fevereiro a agosto/2002) } \\
\hline & \multicolumn{4}{|c|}{ MSPAEx $\left(\right.$ gplanta $\left.^{-1}\right)$} \\
\hline Consórcio & \multicolumn{4}{|c|}{ 9,67 B } \\
\hline \multirow[t]{3}{*}{ Monocultivo } & \multicolumn{4}{|c|}{$12,04 \mathrm{~A}$} \\
\hline & \multicolumn{4}{|c|}{ MSPAIn (gplanta ${ }^{-1}$ ) } \\
\hline & 0 DAT & 14 DAT & 28 DAT & $42 \mathrm{DAT}$ \\
\hline Consórcio & $6,23 \mathrm{Ba}$ & $4,10 \mathrm{Bb}$ & $1,67 \mathrm{Bc}$ & $1,00 \mathrm{Bc}$ \\
\hline Monocultivo & 13,17 Аа & $11,24 \mathrm{Ab}$ & $11,54 \mathrm{Ab}$ & 9,37 Ac \\
\hline
\end{tabular}

${ }^{1}$ DAT = dia após o transplantio do tomateiro; ${ }^{2}$ Médias nas colunas e nas linhas seguidas por letras iguais maiúsculas e minúsculas, respectivamente, não diferem entre si, a $5 \%$ de probabilidade pelo Teste Tukey.

Ciênc. agrotec., Lavras, v. 29, n. 1, p. 77-83, jan./fev. 2005 
Influência das épocas de cultivo e do estabelecimento do consórcio...

81

TABELA 3 - Massa fresca da parte aérea de plantas de alface situadas nas laterais do canteiro (MFPAEx) e internamente no canteiro (MFPAIn), em função do sistema de cultivo e época de transplantio de alface, na $1^{\mathrm{a}}$ e $2^{\mathrm{a}}$ época de cultivo. UNESP, Jaboticabal (SP), 2002.

$1^{\mathrm{a}}$ época de cultivo (julho a novembro/2001)

\begin{tabular}{|c|c|c|c|c|}
\hline \multirow[t]{2}{*}{ Sistema de cultivo } & \multicolumn{4}{|c|}{ MFPAEx (gplanta ${ }^{-1}$} \\
\hline & O DAT ${ }^{1}$ & 14 DAT & 28 DAT & 42 DAT \\
\hline Consórcio & $112,51 \mathrm{Ba}^{2}$ & $98,33 \mathrm{Ba}$ & $52,52 \mathrm{Bb}$ & $15,78 \mathrm{Bc}$ \\
\hline \multirow[t]{2}{*}{ Monocultivo } & $152,21 \mathrm{Aab}$ & $126,38 \mathrm{Ab}$ & 146,58Aab & $169,04 \mathrm{Aa}$ \\
\hline & \multicolumn{4}{|c|}{ MFPAIn (gplanta ${ }^{-1}$ ) } \\
\hline Consórcio & $113,77 \mathrm{Ba}$ & $65,47 \mathrm{Bb}$ & $23,17 \mathrm{Bc}$ & $10,32 \mathrm{Bc}$ \\
\hline \multirow[t]{3}{*}{ Monocultivo } & 173,47Aab & $132,52 \mathrm{Ac}$ & 165,57Aabc & $188,84 \mathrm{Aa}$ \\
\hline & \multicolumn{4}{|c|}{$2^{a}$ época de cultivo (fevereiro a agosto/2002) } \\
\hline & \multicolumn{4}{|c|}{ MFPAEx $\left(\right.$ gplanta $\left.^{-1}\right)$} \\
\hline Consórcio & \multicolumn{4}{|c|}{164,99 B } \\
\hline \multirow[t]{3}{*}{ Monocultivo } & \multicolumn{4}{|c|}{$213,60 \mathrm{~A}$} \\
\hline & \multicolumn{4}{|c|}{ MFPAIn (gplanta ${ }^{-1}$ ) } \\
\hline & 0 DAT & $14 \mathrm{DAT}$ & $28 \mathrm{DAT}$ & $42 \mathrm{DAT}$ \\
\hline Consórcio & $125,37 \mathrm{Ba}$ & $80,73 \mathrm{Bb}$ & $31,6 \mathrm{Bc}$ & $20,80 \mathrm{Bc}$ \\
\hline Monocultivo & 243,16 Аа & $206,81 \mathrm{Ab}$ & $212,85 \mathrm{Ab}$ & $167,72 \mathrm{Ab}$ \\
\hline
\end{tabular}

${ }^{1}$ DAT = dia após o transplantio do tomateiro; ${ }^{2}$ Médias nas colunas e nas linhas seguidas por letras iguais maiúsculas e minúsculas, respectivamente, não diferem entre si, a $5 \%$ de probabilidade pelo Teste Tukey.

Na segunda época de cultivo, houve interação significativa dos fatores avaliados somente para MSPAIn e MFPAIn. Para ambos os casos, observou-se que maior massa seca e fresca da parte aérea de plantas de alface ocorreram em monocultivo. Em sistema consorciado, houve redução no acúmulo de MSPAIn e MFPAIn à medida que mais tardio foi o transplantio da alface. Esta redução no acúmulo foi mais pronunciada quando a alface foi transplantada aos 28 e 42 dias após o transplantio do tomateiro (Tabelas 2 e 3$)$.

Os índices de Uso Eficiente da Terra (UET) mostraram-se bastante influenciados pela época de cultivo. Na primeira época, os valores de UET foram de 1,64; 1,73 ; 1,24 ; e 1,07 , respectivamente, para consórcios estabelecidos aos zero, 14, 28 e 42 DAT. Verificou-se redução de, aproximadamente, 25 e 35\% na eficiência do consórcio quando foi estabelecido aos 28 e 42 DAT em relação ao consorciado com transplantio das espécies conjuntamente. Os consórcios realizados no período de fevereiro a agosto de 2002 apresentaram, em geral, índices de UET superiores aos observados no cultivo de julho a novembro de 2001. Para os consórcios estabelecidos com transplantio da alface aos zero, 14, 28 e 42 DAT do tomateiro, foram obtidos índices de 1,$79 ; 1,61 ; 1,54$ e 1,48 . As reduções observadas entre os consórcios estabelecidos com maior atraso no transplantio da alface em relação ao consórcio com transplantios de alface e tomateiro na mesma data, foram muito menores às observadas na primeira época, não alcançando $15 \%$ entre os consórcios estabelecidos aos zero e 42 DAT. Os maiores índices observados na segunda época de cultivo, bem como as menores reduções observadas entre os consórcios estabelecidos aos zero e 42 DAT, devem-se a menor participação (representatividade) da alface na composição 
do índice, uma vez que nesta época de cultivo, a produtividade do tomateiro foi muito superior (100\% superior) à primeira época .

Ainda que tenha sido constatada vantagem produtiva dos consórcios estabelecidos a partir de 28 DAT, com índices UET superiores a 1, estes consórcios não devem ser recomendados pois, a alface, tanto localizada na lateral como internamente ao canteiro, não apresentou características comerciais, conforme discutido anteriormente.

Diante dos resultados observados, recomendase o cultivo consorciado do tomateiro e alface, nas duas épocas de plantio avaliadas, desde que a alface seja transplantada até 14 dias após o transplantio do tomateiro, podendo-se obter entre 61 e $79 \%$ de incremento na quantidade de alimento produzido por unidade de área.

\section{CONCLUSÕES}

A produtividade comercial do tomateiro e a classificação de frutos de tomate não diferiram segundo o sistema de cultivo (consórcio ou monocultivo).

A produtividade da alface foi menor no cultivo consorciado do que em monocultivo e quanto mais tardio foi o transplantio da alface em relação ao tomateiro, maior foi a redução no acúmulo de massa seca de plantas de alface, nas duas épocas de cultivo.

Com base no índice UET e qualidade comercial da alface, recomenda-se o cultivo consorciado de tomateiro e alface, com o transplantio dessa até 14 dias após o transplantio do tomateiro.

\section{AGRADECIMENTOS}

À FAPESP, pelo auxílio à pesquisa (2000/09675-0) e bolsa de iniciação científica (2000/07941-5), e à UNESP- Campus de Jaboticabal.

\section{REFERÊNCIAS BIBLIOGRÁFICAS}

BEETS, W. C. Multiple-cropping. World Crop Livestock, London, v. 29, p. 25-27, 1975.

CAETANO, L. C. S.; FERREIRA, J. M.; ARAÚJO, M. L. Avaliação do consórcio cenoura e alface na região de Campos dos Goyatazes. Horticultura Brasileira, Brasília, v. 14, n. 1, p. 76, 1996.
CATELAN, F. et al. Análise econômica das culturas de alface e rabanete, cultivadas em monocultivo e consórcio. Horticultura Brasileira, Brasília, v. 20, n. 2, p. 14, 2002. Suplemento.

CECÍLIO FILHO, A. B.; MAY, A. Produtividade das culturas de alface e rabanete em função da época de estabelecimento do consórcio, em relação a seus monocultivos. Horticultura Brasileira, Brasília, v. 20, n. 3, p. 501-504, 2002.

CECÍLIO FILHO, A. B.; TAVEIRA, M. C. G. S.; GRANGEIRO, L. C. Productivity of the beet culture in function of time of establishment of the intercropping with roquete. Acta Horticulturae, The Hague, v. 607, p. 91-95, 2003.

CERETTA, C. A. Sistema de cultivo de mandioca em fileiras simples e duplas em monocultivo e consorciada com girassol. 1986. 122 f. Dissertação (Mestrado em Fitotecnia) - Universidade Federal do Rio Grande do Sul, Porto Alegre, 1986.

DUBEY, D. N.; KULVI, G. S. Performace of sorgghum (Sorghum bicolor) as influencie $\mathrm{Yb}$ intercropping and plantig geometry. Indian Journal of Agronomy, New Delhi, v. 9, p. 353-356, 1995.

FERREIRA, R. F.; CECÍLIO FILHO, A. B. Rendimento de raízes tuberosas de cenoura e rabanete em cultivo consorciado. Horticultura Brasileira, Brasília, v. 19, n. 2, p. 1-4, 2001. Suplemento.

GODE, D. B.; BOBDE, G . N. Intercropping of soybeanim sorghum. PKV-Research Journal, [S.l.], v. 17, n. 2, p. 128-129, 1993.

HORWITH, B. A role for intercropping in modern agriculture. BioScience, Washington, v. 35, n. 4, p. 286-291, 1985.

NARDIN, R. R.; CATELAN, F.; CECILIO FILHO, A. B. Efeito do cultivo intercalado de rúcula e beterraba estabelecida por semeadura direta, sobre as produtividades das culturas. Horticultura Brasileira, Brasília, v. 20, n. 2, p. 1-4, 2002. Suplemento.

PAL, M. S.; SINGH, O. H. Effect of sorghum based intercropping systems on productivity, land equivalent ratio and economics in mollisols of maomotaça tarao (U.P.) Indian Journal of Agronomy, New Delhi, v. 36, n. 1, p. 12-16, 1991. 
REZENDE, B. L. A.; CANATO, G. H. D.; CECÍLIO FILHO, A. B. Consorciação de alface e rabanete em diferentes espaçamentos e épocas de estabelecimento do consórcio, no inverno. Horticultura Brasileira, Brasília, v. 20, n. 2, p. 1-4, 2002a. Suplemento.

REZENDE, B. L. A.; CANATO, G. H. D.; CECÍLIO FILHO, A. B. Produtividade das culturas de tomate e alface em função da época de estabelecimento do consórcio, em relação a seus monocultivos, no cultivo de inverno. Horticultura Brasileira, Brasília, v. 20, n. 2, p. 1-4, 2002b. Suplemento.

REZENDE, B. L. A.; CANATO, G. H. D.; CECÍLIO FILHO, A. B. Productivity of lettuce and radish cultivations as a function of spacing and of time of establishment of intercropping. Acta Horticulturae, The Hague, v. 607, p. 97-101, 2003.

TRENBATH, B. R. Plant interactions in mixed crop communities. In: PAPENDICK, R. I.; SANCHES, P. A.; TRIPLE, G. B. (Eds.). Multiple cropping. Wisconsin: American Society of Agronomy, 1975. p. 129-160.

ZAFFARONI, E. dos. Yield stability of sole and intercropping systems in the northeast of Brazil.

Pesquisa Agropecuária Brasileira, Brasília, v. 22, n. 4, p. 393-399, 1987. 